\title{
Single-Incision Laparoscopic Cholecystectomy after Endoscopic Nasogallbladder Drainage: A Case Report
}

\author{
Tsuyoshi Igami Tomoki Ebata Yukihiro Yokoyama Gen Sugawara \\ Takashi Mizuno Junpei Yamaguchi Masato Nagino \\ Division of Surgical Oncology, Department of Surgery, Nagoya University Graduate School of Medicine, \\ Nagoya, Japan
}

\section{Key Words}

Endoscopic nasogallbladder drainage $\cdot$ Single-incision laparoscopic cholecystectomy $\cdot$ Single-incision laparoscopic surgery

\begin{abstract}
Objective: To report a single-incision laparoscopic cholecystectomy (SILC) for a patient with cholecystitis that required endoscopic nasogallbladder drainage (ENGBD). Clinical Presentation and Intervention: A 75-year-old man was diagnosed with moderate acute cholecystitis and underwent antiplatelet therapy for a history of brain infarction. An ENGBD was performed as an initial treatment for his cholecystitis. After recovery from the cholecystitis, a SILC was performed using a SILS Port with an additional forceps. Because neither Rouviere's sulcus nor Calot's triangle could be identified with a favorable laparoscopic view, the fundus-first procedure was selected. The patient's postoperative course was uneventful, and he was discharged from the hospital on day 3 after surgery. Conclusion: In this case of a patient who had cholecystitis that required ENGBD, a SILC was successful performed using a combination of SILS Port with additional forceps and fundus-first procedure.

(c) 2015 S. Karger AG, Basel
\end{abstract}

\section{Introduction}

Since single-incision laparoscopic cholecystectomy (SILC) was introduced by Navarra et al. [1], it has been widely accepted as a suitable procedure for patients with gallbladder stones without inflammation. Although SILC is recognized as a potentially difficult procedure for patients with cholecystitis, the indication for SILC has been gradually extended to such patients [2]. More recently, we introduced a SILC procedure for patients after percutaneous transhepatic gallbladder drainage (PTGBD) [3]. We herein describe our procedure of a successful outcome with SILC after an endoscopic nasogallbladder drainage (ENGBD).

\section{Case Report}

A 75-year-old man was diagnosed with acute cholecystitis resulting from gallbladder stones accompanied by abdominal pain; the patient was referred to our hospital for further investigation and treatment. On admission to our hospital, the white blood cell

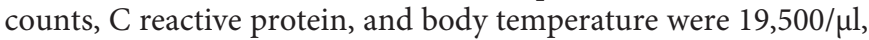
$23.18 \mathrm{mg} / \mathrm{dl}$, and $39.2{ }^{\circ} \mathrm{C}$, respectively. Computed tomography with contrast enhancement showed the wall thickness of the gallbladder including gallstones (fig. 1a) and a small amount of ascites around the liver surface (fig. 1b). Based on these, the severity of the

\begin{tabular}{ll}
\hline KARGER 125\% & $\begin{array}{l}\text { (1) 2015 S. Karger AG, Basel } \\
\text { 1011-7571/15/0245-0496\$39.50/0 Openger }\end{array}$ \\
$\begin{array}{l}\text { E-Mail karger@karger.com } \\
\text { www.karger.com/mpp }\end{array}$ & $\begin{array}{l}\text { This is an Open Access article licensed under the terms of the } \\
\text { Creative Commons Attribution-NonCommercial 3.0 Un- } \\
\text { ported license (CC BY-NC) (www.karger.com/OA-license), } \\
\text { applicable to the online version of the article only. Distribu- } \\
\text { tion permitted for non-commercial purposes only. }\end{array}$
\end{tabular}

Tsuyoshi Igami, $\mathrm{MD}, \mathrm{PhD}$

Division of Surgical Oncology, Department of Surgery

Nagoya University Graduate School of Medicine

65 Tsurumai-cho, Showa-ku, Nagoya 466-8550 (Japan)

E-Mail igami@med.nagoya-u.ac.jp 
Fig. 1. Preoperative images. a The axial view by computed tomography with contrast enhancement showed the wall thickness of the gallbladder (broken arrows) and gallstones (solid arrows). b The coronal view by computed tomography with contrast enhancement showed the wall thickness of the gallbladder (broken arrows) and a small amount of ascites around the liver surface (solid arrows). c Endoscopic retrograde cholangiography revealed an obstruction of the cystic duct (solid arrow). d A 6-Fr catheter (solid arrow) was inserted into the gallbladder through the cystic duct.

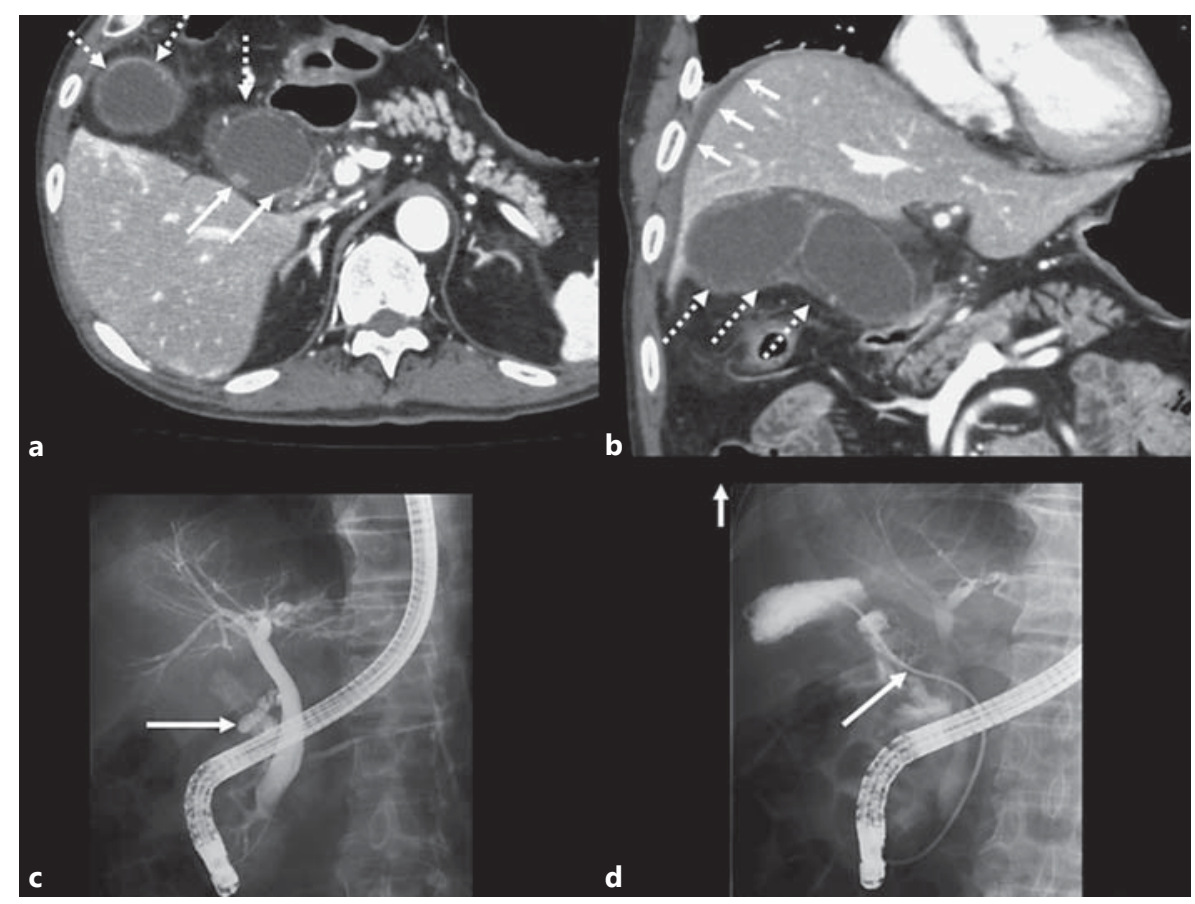

cholecystitis was classified as grade II (moderate acute cholecystitis) [4]. Because the patient was administered aspirin and nicergoline due to a history of brain infarction, we selected ENGBD for the initial cholecystitis treatment $[5,6]$. The endoscopic retrograde cholangiography revealed an obstruction of the cystic duct (fig. 1c), and an ENGBD was then performed to release the obstruction (fig. 1d). The external bile via the ENGBD catheter was purulent, and the bile culture revealed the following types of bacteria: Citrobacter freundii, Enterococcus gallinarum, and Klebsiella pneumoniae. Recovery from cholecystitis and from the external bile condition required 2 weeks of antimicrobial therapy. After 1 week's cessation of the patient's aspirin and nicergoline treatment regime, we planned his surgery for 27 days after the ENGBD.

The SILC using the SILS Port (Covidien, Mansfield, Mass., USA) with an additional 5-mm forceps through an umbilical incision was performed according to our previous reports [2, 3]. The patient was placed in the reverse Trendelenburg position, and the operating surgeon and the assistant surgeon stood at the patient's leg and left side, respectively. A single $2-\mathrm{cm}$ vertical incision was made across the umbilicus. The SILS Port was placed through the umbilical incision, and the 3 holes of the SILS Port were placed at the 1,5, and 9 o'clock positions of the umbilical incision (fig. 2a). After three 5-mm ports were placed into the holes of the SILS Port with a $12-\mathrm{mm} \mathrm{Hg}$ pneumoperitoneum using carbon dioxide, a 5 -mm flexible scope was inserted through the port positioned at 5 o'clock to explore the abdominal cavity. An additional 5-mm forceps was inserted through the umbilical incision at the 7 o'clock position outside the SILS Port to lift the fundus. A 5-mm flexible instrument for the infundibulum was inserted through the port positioned at 9 o'clock, and a 5-mm straight instrument was inserted through the port positioned at 1 o'clock. Because severe inflammation stiffened the gallbladder wall, neither Rouviere's sul- cus (fig. 2b) nor Calot's triangle (fig. 2c) could be identified under a favorable laparoscopic view. To avoid a bile duct injury, the initial dissection of the gallbladder was begun from the fundus using laparosonic coagulating shears (fig. 2d). After dissecting the gallbladder from the gallbladder bed and removing the ENGBD catheter, encirclement of the cystic artery and the cystic duct could be performed (fig. 2e). Because the cystic artery could not be separated from the cystic duct, the structures were cut together using an endoscopic linear stapler (Endo GIA ${ }^{\mathrm{TM}}$, Tri-Staple ${ }^{\mathrm{TM}}$, Covidien), based on our previous report [3] (fig. 2f). The gallbladder was placed inside a retrieval bag. After irrigation of the abdominal cavity, the specimen was removed through the umbilical incision. The umbilical incision was carefully closed without the use of drainage tubes. The operative time and intraoperative blood loss were 104 min and $3 \mathrm{ml}$, respectively.

The macroscopic analysis of the resected specimen did not show any tumor, but 3 mixed stones were in the gallbladder. The histological findings of the gallbladder revealed severe inflammation without malignant disease. The patient's postoperative course was uneventful, and he was discharged from the hospital on day 3.

\section{Discussion}

In this report, our patient had undergone antiplatelet therapy; ENGBD was selected for the treatment of acute cholecystitis, and the treatment was successful. Generally, antimicrobial therapy with or without gallbladder drainage has been recommended as the initial treatment of moderate acute cholecystitis $[5,6]$. When gallbladder 


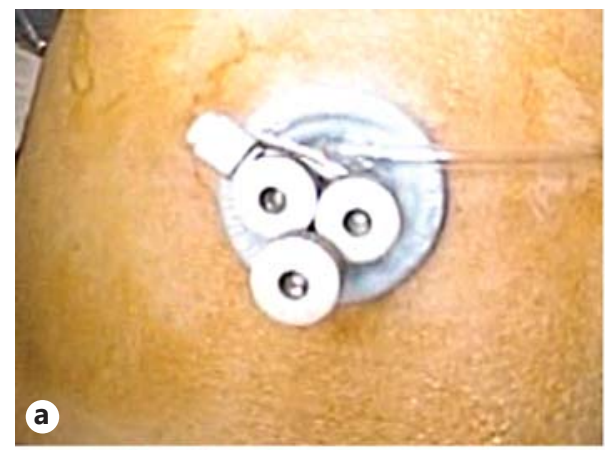

Fig. 2. Intraoperative findings. a A SILS Port (Covidien) was placed through the umbilical incision, and the 3 holes of the SILS Port were placed at the 1,5 , and 9 o'clock positions of the umbilical incision. b Rouviere's sulcus could not be identified because the lift of the infundibulum was insufficient. c Calot's triangle could not be identified because of severe inflammation. d Initial dissection of the gallbladder was started from the fundus using laparosonic coagulating shears. e After dissecting the gallbladder from the gallbladder bed, the cystic artery (red arrow) and the cystic duct (green arrows) were encircled together; however, the fat tissue around the cystic duct (yellow arrows) could not be separated from the cystic duct (colors refer to the online version only). $\mathbf{f}$ After the cystic duct and the cystic artery were cut together by an endoscopic linear stapler (Endo GIA ${ }^{\mathrm{TM}}$, Tri-Staple ${ }^{\mathrm{TM}}$, Covidien), neither bile leakage nor bleeding from the stump of both structures (white arrows) was observed.

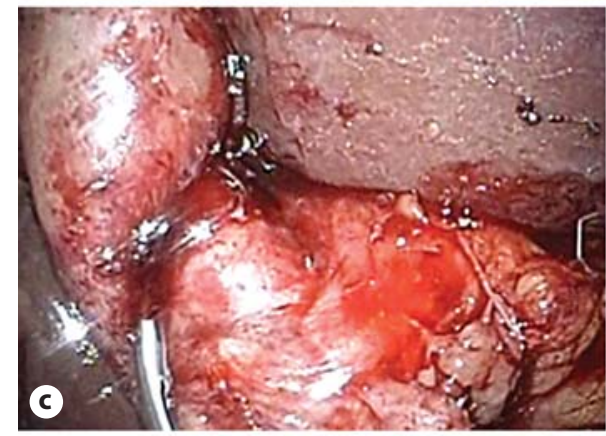

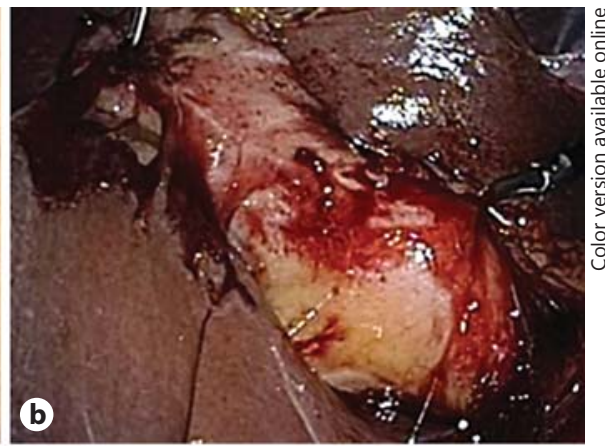

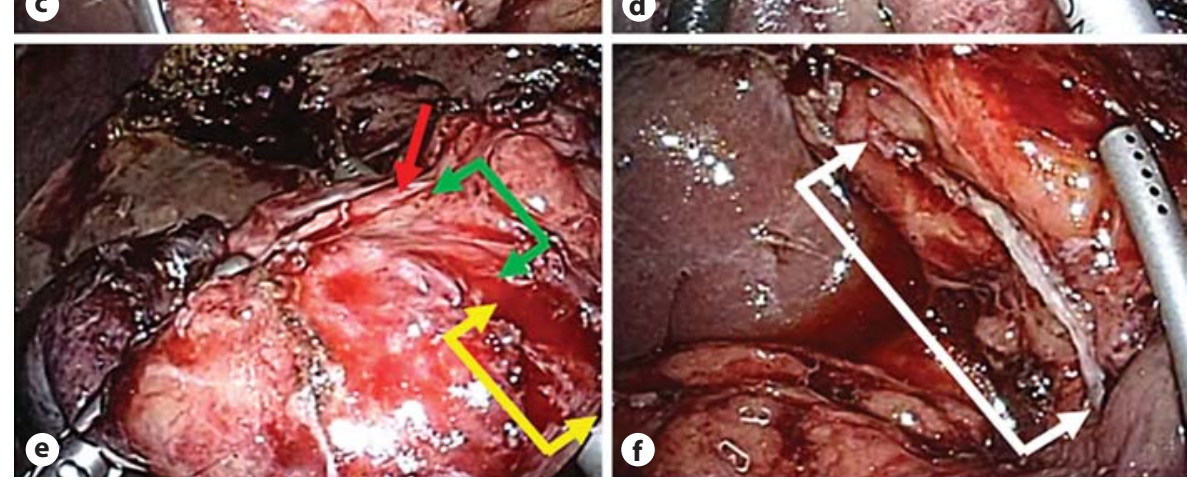

drainage is required for the treatment of complicated acute cholecystitis, PTGBD has been widely accepted [6]; PTGBD for patients on anticoagulant and/or antiplatelet therapies is difficult. Recently, the selection of ENGBD for such patients has incrementally increased $[6,7]$. According to previous reports, PTGBD is recognized as a valuable procedure and has led to a reduction in postoperative complications in early and delayed conventional laparoscopic cholecystectomies $[8,9]$. Recently, it has been reported that ENGBD was similarly valuable in early conventional laparoscopic cholecystectomies [7]. The value of ENGBD for delayed laparoscopic cholecystectomy has been unclear. In this report, neither Rouviere's sulcus nor Calot's triangle could be identified with a favorable laparoscopic view, and the cystic artery could not be separated from the cystic duct after the fundus-first and dome-down resection. These factors might be attributed to the inflam- mation of the cystic duct and its surrounding fat tissue, which was associated with how long an ENGBD catheter remained indwelling. Further investigations are required to establish the safety of the procedure for delayed laparoscopic cholecystectomy after ENGBD.

According to our previous report [3], SILC after PTGBD could be safely performed without intraoperative or postoperative complications. The essential factors of our procedure involved the following: (1) utilization of the SILS Port with an additional forceps through the umbilical incision facilitated maneuverability during the SILC, and the maneuverability was comparable to that of a conventional laparoscopic cholecystectomy, and (2) when the cystic artery could not be separated from the cystic duct after the fundus-first and dome-down resection, using the endoscopic linear stapler to cut the structures together avoided inadvertent bleeding and bile duct injury. In this 
report, although the fundus-first and dome-down resection procedure [10], which is a more demanding procedure, was selected, we were unaffected by its maneuverability. Cutting the cystic artery and the cystic duct together using an endoscopic linear stapler could be easily and safely performed without intraoperative complications.

\section{Conclusion}

In this case of a patient who had cholecystitis that required ENGBD, a SILC was successfully performed using a combination of SILS Port with additional forceps and fundus-first procedure.

\section{References}

-1 Navarra G, Pozza E, Occhionorelli S, et al: One-wound laparoscopic cholecystectomy. Br J Surg 1997;84:695.

-2 Igami T, Usui H, Ebata T, et al: Single-incision laparoscopic cholecystectomy for porcelain gallbladder: a case report. Asian J Endosc Surg 2013;6:52-54.

$>3$ Igami T, Aoba T, Ebata T, et al: Single-incision laparoscopic cholecystectomy for cholecystitis requiring percutaneous transhepatic gallbladder drainage. Surg Today 2015;45: 305-309.

-4 Yokoe M, Takada T, Strasberg SM, et al: TG13 diagnostic criteria and severity grading of acute cholecystitis (with videos). J Hepatobiliary Pancreat Sci 2013;20:35-46.
5 Miura F, Takada T, Strasberg SM, et al: TG13 flowchart for the management of acute cholangitis and cholecystitis. J Hepatobiliary Pancreat Sci 2013;20:47-54.

6 Tsuyuguchi T, Itoi T, Takada T, et al: TG13 indications and techniques for gallbladder drainage in acute cholecystitis (with videos). J Hepatobiliary Pancreat Sci 2013;20:81-88.

7 Toyota N, Takada T, Amano H, et al: Endoscopic naso-gallbladder drainage in the treatment of acute cholecystitis: alleviates inflammation and fixes operator's aim during early laparoscopic cholecystectomy. J Hepatobiliary Pancreat Surg 2006;13:80-85.
8 Chikamori F, Kuniyoshi N, Shibuya S, et al: Early scheduled laparoscopic cholecystectomy following percutaneous transhepatic gallbladder drainage for patients with acute cholecystitis. Surg Endosc 2002;16:1704-1707.

9 Kim HO, Son BH, Yoo CH, et al: Impact of delayed laparoscopic cholecystectomy after percutaneous transhepatic gallbladder drainage for patients with complicated acute cholecystitis. Surg Laparosc Endosc Percutan Tech 2009;19:20-24.

10 Patel AG, Murqatroyd B, Carswell K, et al: Fundus-first transumbilical single-incision laparoscopic cholecystectomy with a cholgiogram: a feasibility study. Surg Endosc 2011; 25:954-957. 